\title{
Catalytic Hydrogenation in the Liquid Phase
}

\author{
Felix Roessler*
}

\begin{abstract}
Catalytic hydrogenation in the liquid phase is a very common reaction type in the production of fine chemicals and pharmaceuticals. Among the various reaction techniques, it is the slurry technique (stirred tank or venturi type loop reactor) in a semi-batch mode which is most frequently used. General safety aspects of catalytic hydrogenations will be discussed und exemplified for a typical three-phase semi-batch catalytic hydrogenation.
\end{abstract}

Keywords: Catalytic hydrogenation $\cdot$ Hydrogen $\cdot$ Metal catalyst · Safety

\section{Introduction}

Three-phase catalytic hydrogenations are reactions that can generally be carried out with low risk provided that proper precautions are followed. Within the Roche company about $10 \%$ of all chemical steps in the synthesis of pharmaceuticals, vitamins and fine chemicals are catalytic hydrogenations. Despite this high proportion of catalytic hydrogenations, no noteworthy incidents occurred in the last few decades. Nevertheless, incidents with catalytic hydrogenations occasionally take place, as is shown in the following examples.

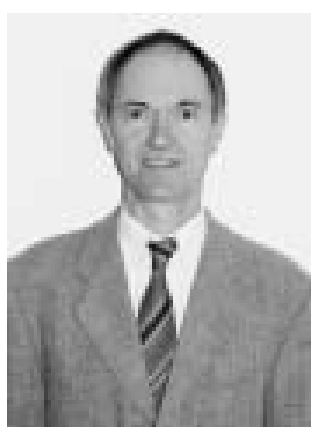

${ }^{*}$ Correspondence: F. Roessler Roche Vitamins AG $\mathrm{CH}-4303$ Kaiseraugst Tel.: + 41616872713 Fax: +41616872201 F-Mail: felix.roessler@roche com

\section{Incident no. 1}

(Decomposition in the hydrogenation of a nitroaromatic compound)

In 1976 a violent explosion occurred at Du Pont de Nemours Co., Deepwater, NJ with destruction of plant and plant building [1]. The explosion occurred during the hydrogenation of 3,4-dichloro-nitrobenzene.

The analysis of the process of explosion gave the following picture: (1) Hydrogen uptake ceased before complete conversion; (2) in order to complete the conversion, the temperature in the reactor was increased by heating; (3) the consequence was a violent explosion.

Analysis of the chemistry showed: (1) Reaction path of desired reaction: $\mathrm{ArNO}_{2}$ $\rightarrow \mathrm{ArNO} \rightarrow \mathrm{ArNHOH} \rightarrow \mathrm{ArNH}_{2}(\mathrm{Ar}=$ aromatic ring system); (2) possible side reactions: Disproportionation of $\mathrm{ArNHOH}(2$ $\mathrm{ArNHOH} \rightarrow \mathrm{ArNO}+\mathrm{ArNH}_{2}+\mathrm{H}_{2} \mathrm{O}$ ), coupling reactions with formation of azoxy-, azo-, and hydrazo compounds, autodecomposition reactions of nitroaromatic compounds and arylhydroxylamines (potential explosives).

Kinetics of the reaction: First and second step $\left(\mathrm{ArNO}_{2} \rightarrow \mathrm{ArNO} \rightarrow \mathrm{ArNHOH}\right)$ are fast reactions, last step ( $\mathrm{ArNHOH} \rightarrow$ $\mathrm{ArNH}_{2}$ ) is slow and has a high activation energy, i.e. is more temperature sensitive than the first two steps.

Thermodynamics of the reaction: (1) Main reaction is strongly exothermic ( $c a$. $170 \mathrm{~kJ} / \mathrm{mol} \mathrm{H}_{2}$ ); (2) disproportionation reaction, coupling reaction and autodecomposition also strongly exothermic.

Explanation of incident: Accumulation of arylhydroxylamine ArNHOH (probably due to lower quality of nitroaromatic compound and/or catalyst than normal), which upon heating led to disproportionation and coupling reactions with temperature increase which triggered further autodecomposition of these intermediates and runaway reaction with pressure build up in the closed system which finally led to destruction of the hydrogenation vessel and plant building.

Lesson: Never produce chemicals without detailed information on the underlying chemistry of the process (kinetics, thermodynamics, pathways).

\section{Incident no. 2}

(Explosion during steaming of

\section{Raney nickel}

\section{containing residual ethylacetate)}

In 1998 an explosion took place at one of Roche's contract manufacturers. $250 \mathrm{~kg}$ of spent Raney nickel containing residual ethylacetate was treated with hot water steam at 3.5 barg steam $\left(148{ }^{\circ} \mathrm{C}\right)$ in a 6501 backflush filter. During this operation, the pressure in the filter increased to 1.5 barg. Because of this pressure increase, all valves were closed. Nevertheless the pressure further increased to 2.5 barg within $5 \mathrm{~min}$ and after another $20 \mathrm{sec}$ to $15 \mathrm{barg}$. The safety valve opened at $10 \mathrm{barg}$, but the enormously fast pressure build up could not be compensated quickly enough. Therefore the cover of the filter housing was lifted and the pressure was released via the opened flange. As a consequence, it came to ignition of combustible material (mainly hydrogen and ethylacetate). Retrospective analysis showed that the incident was 
caused by liberation of adsorbed hydrogen and reaction of water with residual aluminium in the Raney nickel (and possibly nickel itself) with formation of the metal oxides and hydrogen. Further metal-catalyzed reactions such as hydrogenolysis of ethylacetate with hydrogen in the gas phase (initiated by hot spots) resulting in the formation of methane and other volatile materials were also discussed.

Lesson: Never treat Raney catalysts with hot water or even steam in closed systems.

\section{Incident no. 3}

\section{(Oxyhydrogen explosion in a filter} housing containing catalyst)

In the process of separating used Raney nickel, it came to an explosion in a filter housing. Accidentally it came to a subatmospheric pressure and then suction of air into the filter housing containing solventwet Raney nickel. The reaction of oxygen with adsorbed hydrogen and solvent vapor led to a pressure increase which damaged the filter housing.

Lesson: Never allow subatmospheric pressure in vessels containing combustible materials and/or catalysts before careful total inertization.

\section{Hazards of Catalytic Hydrogenation Processes}

As in every chemical process, hazards in catalytic hydrogenations originate from the materials used in the process and from the reaction of these materials, whereas the reasons for an incident taking place may be of systemic nature (incorrect process design etc.) or a deviation from the design conditions (technical or human error) (Fig $1)$.

\section{Prevention of Incidents}

As is common practice with chemical reactions, precaution and measures for the safe execution of catalytic hydrogenations are subdivided into: (1) Measures for the prevention of explosive mixtures (combustible material, particularly hydrogen/air mixtures) as well as prevention of conditions of reaction runaway (primary explosion protection); (2) measures for the prevention of ignitions by exclusion of ignition sources (secondary explosion protection); (3) measures for the limitation of the consequences of explosions (constructive explosion protection); (4) organizational measures, training of employees and emergency concept.

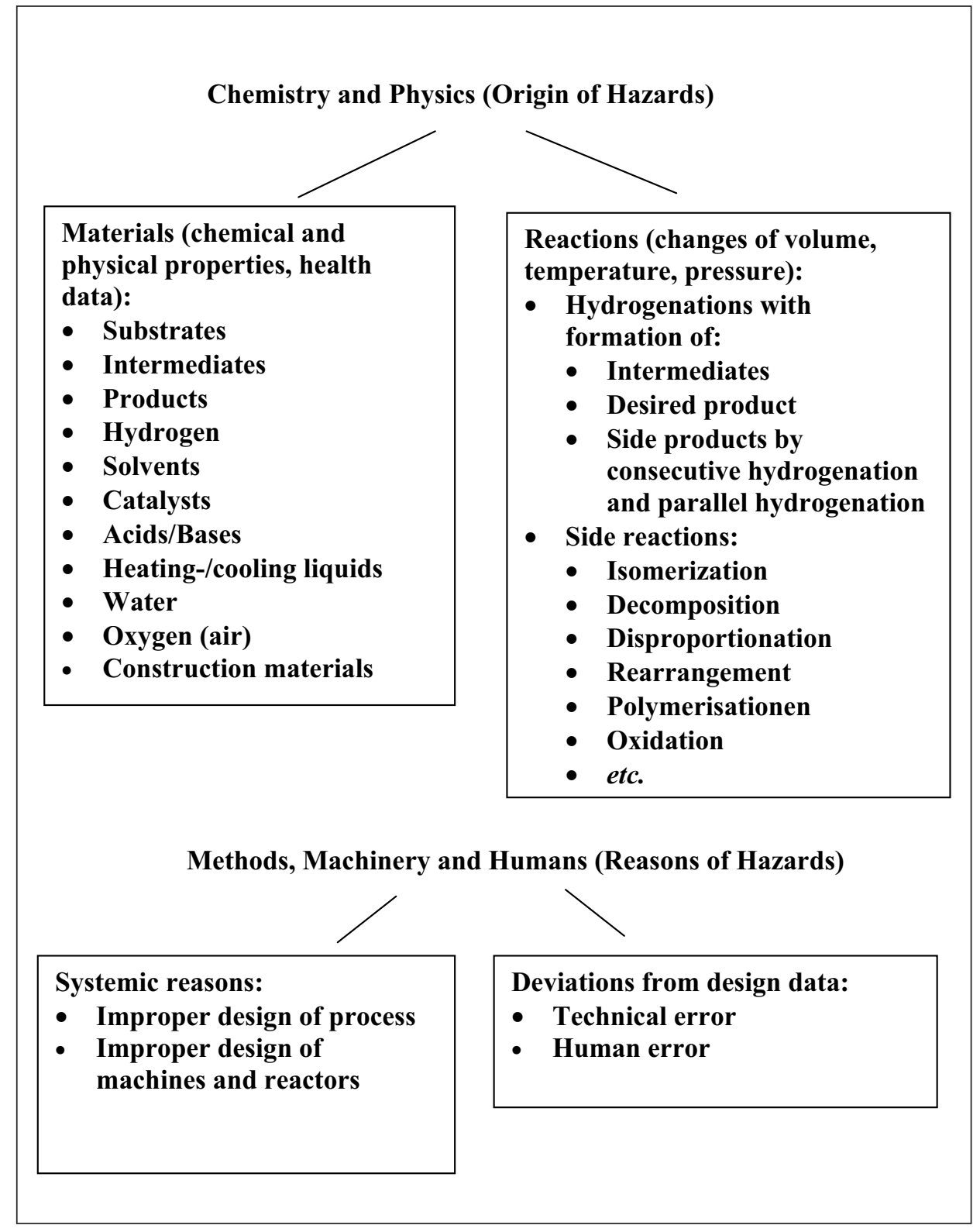

Fig. 1. Origins and reasons of hazards upon performing catalytic hydrogenation

Unlike 'normal chemical reactions', catalytic hydrogenations require special additional attention due to hydrogen being a very energetic and easily ignitable combustible gas and metal catalysts being very potent ignition sources.

Evaluation of hazards of catalytic hydrogenations can be made on the basis of a standard procedure [2]. Such a procedure consists of: (1) Basic information such as data on the process (material and reaction data), (2) data on the plant equipment and (3) data on methods of plant operation. A risk assessment can then be made on the basis of the hazard evaluation.

Both evaluation of hazard data and risk assessment are very process specific. More details on prevention of incidents and risk assessment can be found elsewhere [3].

\section{Hydrogen and Catalyst Specific Properties and Safety Relevant Data}

As mentioned previously, general material data and safety relevant material data are a very important basis for hazard evaluation and risk assessment of catalytic hydrogenations. Hydrogen and metal catalysts need special attention.

\subsection{Hydrogen}

Hydrogen is a very potent, highly energetic combustible material. Some properties of hydrogen are given in Table 1. When working with hydrogen, inertization is a must because of the broad explosion range of hydrogen/air mixtures on one hand and the low ignition energy needed to ignite hy- 
drogen/air mixtures on the other hand. Table 2 gives threshold values for partial and complete inertization.

More safety relevant key data of hydrogen and hydrogen/air mixtures can be found elsewhere [3].

\subsection{Catalysts}

Raney catalysts in particular, but also noble metal catalysts that contain adsorbed hydrogen are pyrophoric and therefore ignite in the presence of air. Spent catalysts are therefore preferably wetted with water before transport for recovery of the metals. Hydrogenation catalysts are very potent ignition sources (lowering of activation energy for reaction of combustible materials with oxygen). Döbereiner made practical use of platinum as an ignition source in 1829 with his invention of the catalytic fire lighter (Fig. 2).

Base metal catalysts (particularly Raney catalysts) can react with water to form metal oxides and hydrogen (pressure increase in closed systems!). Contact of combustible materials in the gas phase with catalysts, particularly Raney catalysts) can lead to hot spots (reaction of adsorbed hydrogen with organic solvents at elevated temperature in the gas phase with formation of hydrogenolysis products and pressure increase in closed systems). It is good practice not to completely dry spent catalysts or preferably to wet them with water.

It should also be borne in mind that powder catalysts can cause dust explosions.

\section{Design of Inherently Safe Hydrogenation Processes}

In order to ensure safe hydrogenation processes, the basic data of the reaction must be well established, i.e. the reaction network (main and side reactions including individual steps of multiple reactions) as well as kinetic (particularly temperature dependence) and thermodynamic data of all these processes and reaction steps must be known.

\subsection{Reaction Network}

Frequent side reactions of catalytic hydrogenations and hydrogenolyses are metal-catalyzed isomerizations, disproportionations and coupling reactions, acid/base catalyzed reactions (due to acid or base traces or properties of the catalyst) as well as consecutive (primary hydrogenation product can be further hydrogenated) and parallel hydrogenations (one particular molecule can undergo different reductions leading to different products). Besides

Table 1. Properties of hydrogen

\section{Properties of hydrogen \\ Colourless and odourless}

Flame almost invisible; flame temperature of stoichiometric mixture of hydrogen in air $\left(29.6 \% \mathrm{H}_{2}\right)$ has flame temperature of $2110{ }^{\circ} \mathrm{C}$ Highly flammable and forms explosive mixtures with air (4-75 vol\% hydrogen), oxygen (4-96 vol\% hydrogen), chlorine (3-92.5 vol\% hydrogen) and many other gases

Deflagration: Deflagrative burning velocity of hydrogen in air is in the order of $3 \mathrm{~m} / \mathrm{s}$;

max. pressure ratio in deflagration is ca. 7 (final pressure/initial pressure)

Detonation: Detonative burning velocity of hydrogen in air is on the order of $2000 \mathrm{~m} / \mathrm{s}$ Autoignition temperature of hydrogen/air mixture $580^{\circ} \mathrm{C}$

High diffusion rate of hydrogen

Low ignition energy $(0.019 \mathrm{~mJ})$ : ignites without apparent ignition source (for comparison: hydrocarbon vapors $0.25 \mathrm{~mJ}$ )

Negative Joule Thomson

Small size of hydrogen molecule makes hydrogen prone to escape via leaks

Storage in gas cylinders

Solubility of hydrogen in solvents

Compatibility of hydrogen with materials

Specific weight low

\section{Table 2. Threshhold values for inertization}

\section{Threshhold values at partial inertization with $\mathbf{N}_{\mathbf{2}}$ :}

Maximum oxygen concentration below $5 \mathrm{~mol} \% \mathrm{O}_{2}$ which no explosive mixtures exist whatsoever the hydrogen concentration will be (LOC)

Minimum ratio of $\mathrm{mol} \mathrm{N}_{2} / \mathrm{mol}$ air above which no explosive mixtures exist whatsoever the hydrogen concentration is (MAl)

Threshhold values at complete inertization with $\mathbf{N}_{\mathbf{2}}$ :

Minimum ratio of $\mathrm{mol} \mathrm{N}_{2} / \mathrm{mol}$ hydrogen, above which no explosive mixtures exist whatsoever the air concentration will be (MXC)
Precautions, comments

Use of hydrogen sensors recommended

Avoid air, proper inertization, be careful with vacuum, good ventilation

Hydrogen spill in open area diffuses rapidly to nonexplosive mixture (2000 liter hydrogen spill in unconfined area will diffuse to an nonexplosive mixture within about one minute).

Ignition even by catalytic effect of surfaces, catalysts

Heat generation upon expansion of pressurized hydrogen

Proper design of piping according NFPA pamphlet $50 \mathrm{H}$ : Standards for gaseous hydrogen systems at consumer sites, National Fire Protection Association, Quincy MA

Gas cylinder must be properly secured (grounded and fixed) and should be stored in a cool and dry and well vented area; handling of compressed gases compare (www.airproducts.com)

Rule of thumb: 0.1 normliter hydrogen per liter of solvent and bar

Compatible with almost all materials; embrittlement of materials that can form solutions with hydrogen (palladium)

Hydrogen has tendency to escape to top, but be careful about this rule of thumb as diffusion rates and draught may dominate this gravity driven escape direction 


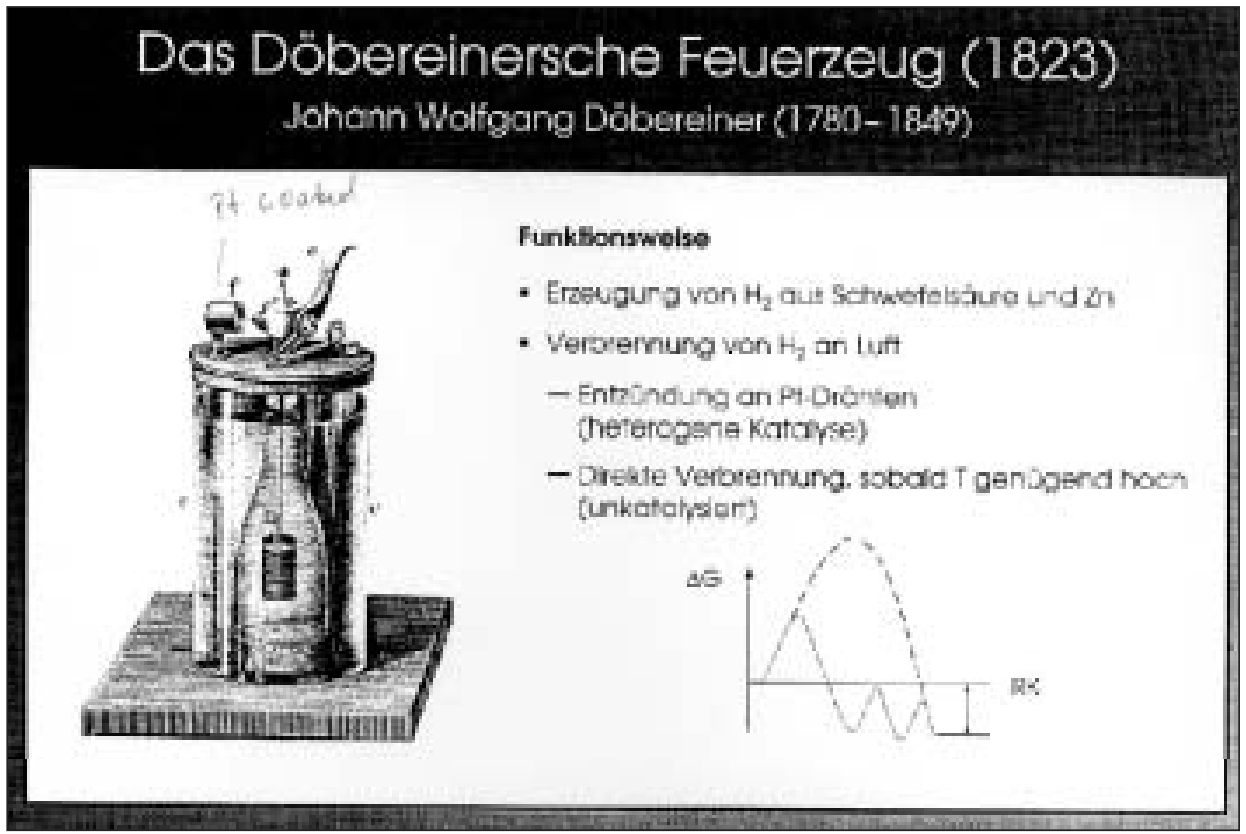

Fig. 2. Döbereiner fire lighter (picture taken from A. Baiker, lecture 1997)

these metal-catalyzed reactions, any other type of thermal reaction can be part of the reaction network.

\subsection{Thermodynamics}

Hydrogenations are generally exothermic (Table 3).

\subsection{Kinetics}

The rate of catalytic hydrogenation is influenced by temperature, amount of catalyst, type of solvent, concentration of substrate (and product) and partial pressure of hydrogen. The rate of the surface reaction can normally best be described by a Langmuir Hinshelwood rate law, which integrates both adsorption as well as reaction rate of adsorbed species into the rate equation.

\subsection{Mass- and Heat Transport, Fluid Dynamics and its Relevance for Safe Hydrogenation Processes}

Heterogeneous catalytic hydrogenations in the liquid phase are three-phase processes. Mass transport, heat transport and fluid dynamics have therefore to be considered in addition to the chemistry. In practice it is the gas/liquid transport (i.e. transport of hydrogen from the gas to the liquid phase) which is of most importance. Depending on the individual conditions, we speak of a reaction in the transport regime (reaction rate is limited by gas/liquid transport rate, i.e. slowest step is the transport of hydrogen from the gas to the liquid phase) or reaction in the kinetic regime (the surface reaction is the slowest step). Whether a hydrogenation takes place in the kinetic or transport limited region can be quickly

Table 3. Average reaction enthalpies of hydrogenations

$\begin{array}{lc}\text { Reaction } & \begin{array}{c}\text { Reaction heat } \\ {\left[\mathbf{k J} / \mathbf{m o l ~ H}_{\mathbf{2}}\right]}\end{array} \\ \text { Carbon-carbon double bond to single bond } & 125 \\ \text { Carbon-carbon triple bond to single bond } & 150 \\ \text { Aromatic ring saturation } & 70 \\ \text { Ketone to alcohol } & 65 \\ \text { Nitro to amine } & 170 \\ \text { Carbon-halogen hydrogenolysis } & 65\end{array}$

found out by stirring speed and catalyst loading experiments in a stirred tank reactor in semi-batch mode.

For a simple power-law rate equation, the hydrogenation rate under equilibrium conditions can be described as represented in Eqn 1:

$$
\begin{aligned}
\mathrm{r}_{\mathrm{obs}} & =\mathrm{k}_{\mathrm{gl}} * \mathrm{a}_{\mathrm{gl}} *\left(\mathrm{c}_{\mathrm{H} 2 \mathrm{~g} / \text {-interface }}-\mathrm{c}_{\mathrm{H} 2 \text { liquidbulk }}\right) \\
& =\mathrm{k}_{\text {react }} * \mathrm{c}_{\text {catalyst }} *\left(\mathrm{c}_{\mathrm{H} 2 \text { liquidbulk }}\right)^{\mathrm{n}} *\left(\mathrm{c}_{\text {substrat }}\right)^{\mathrm{m}}
\end{aligned}
$$

where: $\mathrm{r}_{\text {obs }}=$ observed reaction rate, $\mathrm{k}_{\mathrm{gl}}=$ gas/liquid transport coefficient, $\mathrm{a}_{\mathrm{gl}}=\mathrm{gur}$ face area gas/liquid, $\mathrm{c}_{\mathrm{H} 2 \mathrm{~g} / \text {-interface }}=$ partial pressure of hydrogen at gas liquid interface, $\mathrm{c}_{\mathrm{H} 2 \text { liquidbulk }}=$ partial pressure of hydrogen in bulk liquid, $\mathrm{k}_{\text {react }}=$ reaction rate constant, $\mathrm{c}_{\text {catalyst }}=$ amount of catalyst, $\mathrm{c}_{\text {substrat }}=$ concentration of substrate.

A hydrogenation can therefore always be slowed down (or even turned off) by:

- Minimization of $\mathrm{a}_{\mathrm{gl}}$ (decrease stirring rate or even switching off stirrer)

- Minimization of $\left(\mathrm{c}_{\mathrm{H} 2 \text { g/l-interface }}-\mathrm{c}_{\mathrm{H} 2}\right.$ liquid bulk) by decreasing pressure or feeding inert gas
On the other hand, the hydrogenation rate can be influenced via the rate of the surface reaction per unit volume of reaction solution:

- Temperature $\left(\mathrm{k}_{\text {reaction }}\right.$ is dependent on the temperature)

- Amount of catalyst

- Hydrogen partial pressure if $n>0$

- Substrate concentration if $m>0$

In practice, it is therefore always possible to slow down a rapid heat production in a catalytic hydrogenation by measures such as reduction of the stirring speed, reduction of the pressure, feeding inert gas or switching off the hydrogen supply. Nevertheless 
switching off the hydrogen supply is only a means to stop heat production which is due to reaction of hydrogen.

\subsection{Safety Aspects of Various Hydrogenation Techniques}

Each of the subsequently described hydrogenation techniques has its specific advantages and disadvantages regarding safety.

\subsubsection{Semi-batch}

This is the most frequently used technique in the small to medium scale production of fine chemicals and pharmaceuticals. The substrate is loaded into the reactor as one batch and the hydrogen is fed continuously; the pressure is frequently held constant over the whole cycle time. Due to the limited availability of hydrogen in the reactor (maximum amount of hydrogen in the reactor $=$ hydrogen in the gas phase and hydrogen dissolved in the liquid phase), a high degree of safety is given. An additional safety aspect is the possibility to slow down the reaction by slowing down or even switching off the hydrogen supply.

\subsubsection{Continuous Hydrogenation} in a Continuous Stirred Tank Reactor

In case of an instable starting material, it is possible to run the hydrogenation at a high conversion degree, thus keeping the steady state concentration of instable (and therefore safety relevant) starting material in the reactor low.

\subsubsection{Continuous Hydrogenation in a Catalytic Fixed Bed Reactor}

Due to the generally high catalyst holdup and therefore high timespace yield of tubular fixed bed reactors, the reaction volume can be held small, which is an advantage in the case of an incident.

\section{Case Study of a Semi-batch Hydrogenation}

\subsection{Chemistry}

\subsubsection{Reactions and Reaction} Pathways

The process to be dealt with is the catalytic hydrogenation of a diene to the corresponding saturated alkane. The overall reaction consists of a set of multiple reactions (equilibrium reactions, consecutive and parallel reactions) (Scheme).

\subsubsection{Chemical Kinetics} and Thermodynamics

\subsubsection{Hydrogenation}

(Desired Main Reaction)

Under the chosen reaction conditions (pressure, temperature, stirring frequency,

conversion (Hydrogen)

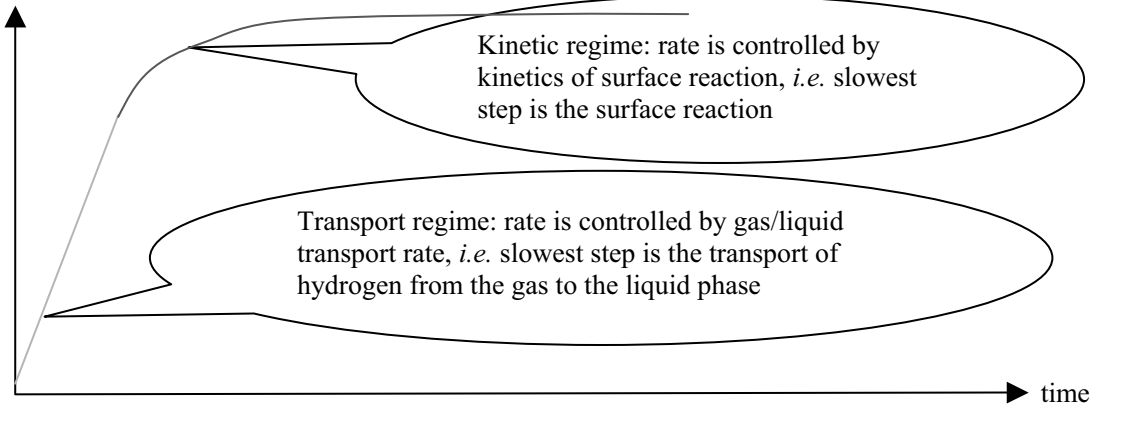

Fig. 3. Time/conversion plot of semi-batch hydrogenation

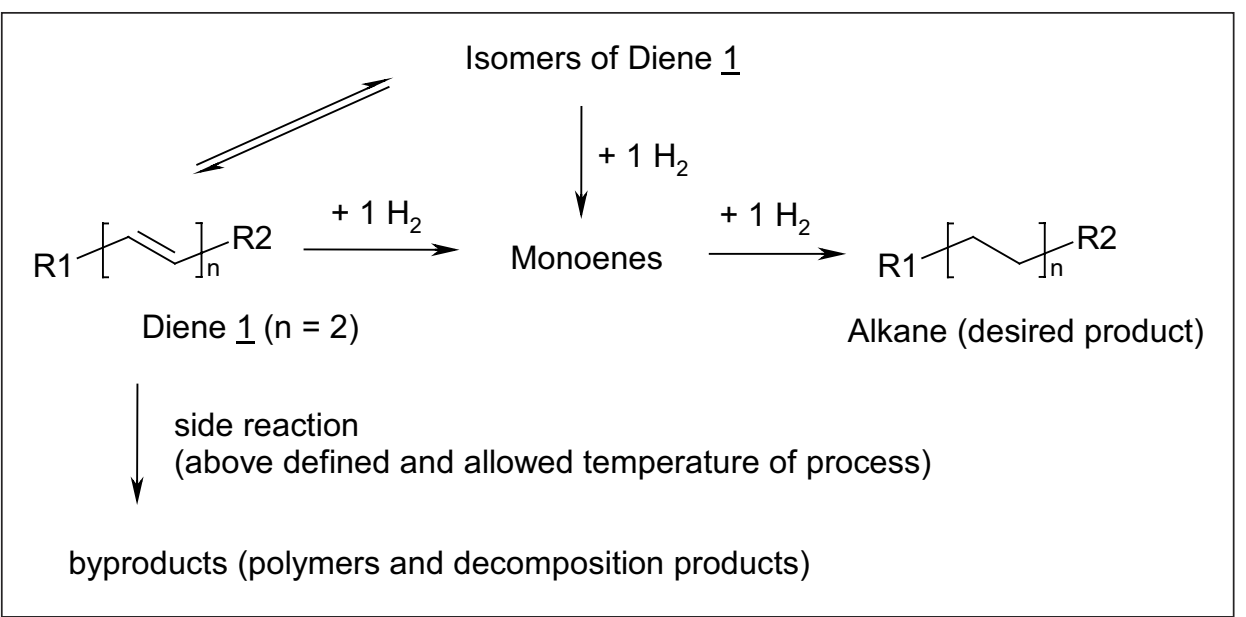

Scheme. Hydrogenation of diene to saturated alkane

amount of catalyst) the hydrogenation is very fast and therefore is mainly gas/liquid transport limited as long as dienes are present in the solution, i.e. the rate of transport of hydrogen from the gas to the liquid phase is the slowest step (slower than the maximum possible surface reaction rate of chemisorbed hydrogen with chemisorbed diene). As soon as all dienes have been converted (mixture then consists of mono-enes and alkanes), the reaction gets slower and transforms to kinetic control (reaction rate determined by rate of surface reaction) (Fig. 3).

The temperature sensitivity of the desired reaction was determined to lie in a normal range (activation energy for conversion of diene to monoene and monoene to alkane in the order of $60 \mathrm{~kJ} / \mathrm{mol}$ ). The reaction enthalpy $\Delta \mathrm{H}$ for diene to alkane was determined with $257 \mathrm{~kJ} / \mathrm{mol}$ diene. The adiabatic temperature increase is very high with $550{ }^{\circ} \mathrm{C}$, as the reaction is carried out in the absence of solvent (diene is a liquid).

\subsubsection{Side Reactions}

Besides hydrogenation reactions, the reaction network is characterized by two main side reactions: (1) Isomerization of diene (isomerization products are finally converted to desired alkane). The rate as well as reaction enthalpy of this reaction is minor compared with the rate and enthalpy of the hydrogenation reaction, but the activation energy is slightly higher, i.e. more temperature sensitive. (2) Polymerization and decomposition of diene; as long as the hydrogenation is run within the design temperature range of the process, the rate of polymerization and decomposition reaction can be neglected. Nevertheless the activation energy for both side reactions is much higher than for the hydrogenation, i.e. a temperature increase favors the polymerization/decomposition reaction and could lead to a runaway situation. Exceeding the upper limit of the design temperature range must therefore be avoided by all means.

\subsection{Reaction Technique}

The hydrogenation is carried out as a slurry three-phase process in a stirred tank reactor in a semi-batch mode, i.e. hydrogen is fed continuously to the batch-fed diene. It will later be explained why this technique was chosen (section 6.4.3). 


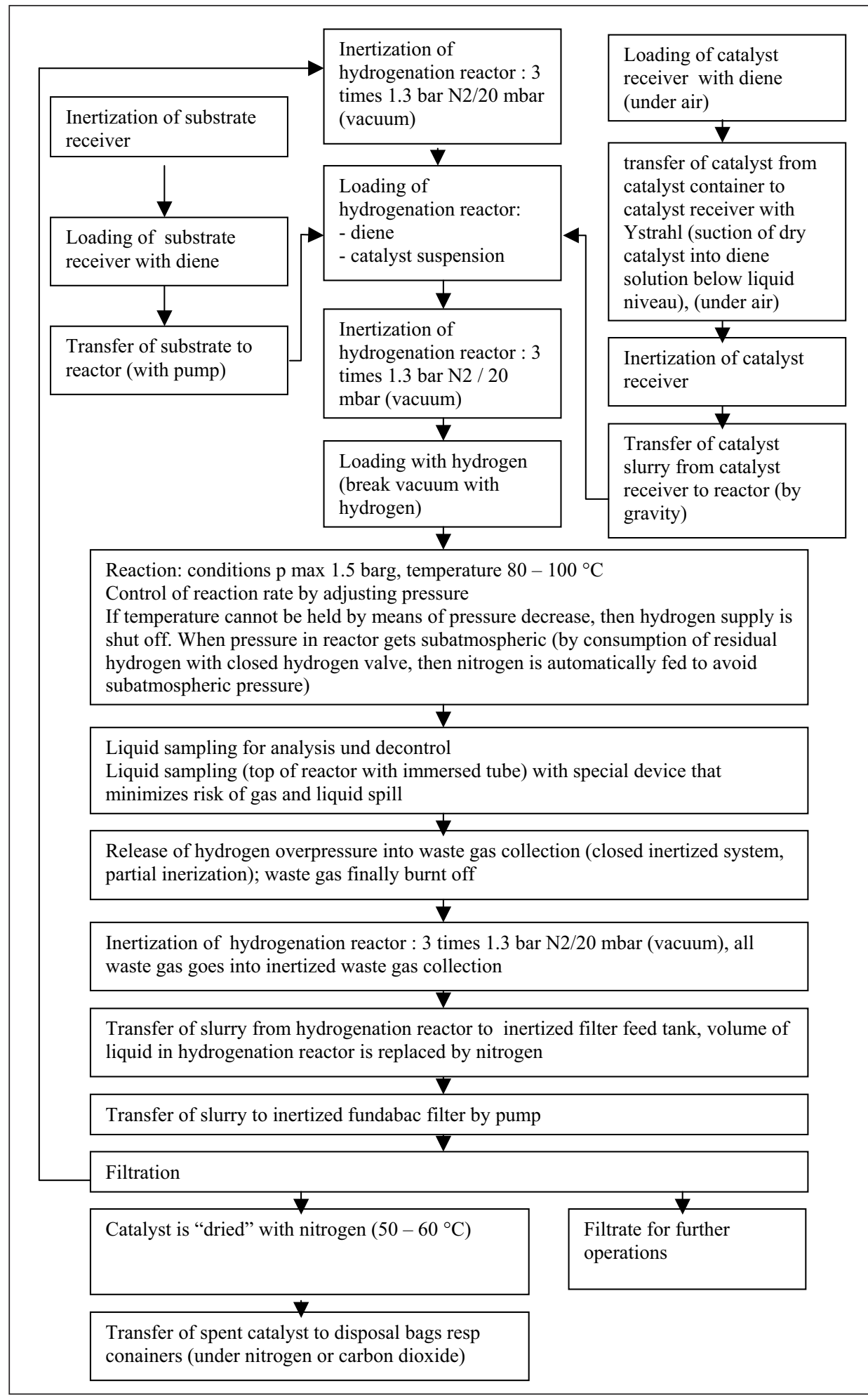

Fig. 4. Hydrogenation process operation steps

\subsection{Results from Hazard Evaluation}

A hazard analysis of the hydrogenation resulted in the following potential hazard/risk potentials: (1) Hydrogen and air form explosive mixtures; (2) catalyst and air form explosive mixtures (dust explosion); (3) very high adiabatic temperature increase of hydrogenation; (4) exothermic autodecomposition of diene at high temperature (upper temperature limit in process is $\left.140{ }^{\circ} \mathrm{C}\right)$; (5) spent catalyst is pyrophoric; (6) ignition sources: catalyst is potent ignition source to ignite hydrogen/air-mixtures, electrostatics; (7) spill from reactor to plant building.

\subsection{Measures Taken to Minimize Risks}

The process operations are schematically represented in Fig. 4 and described in more detail in the following sections.

\subsubsection{Measures to Prevent Dust Explosion (Fresh Catalyst/Air Mixtures) During Loading of Fresh Catalyst}

The dry catalyst is transferred by means of a special device ('Ystrahl-stirrer', Fig. 5) from the catalyst barrel to a catalyst-slurry vessel previously loaded with diene. The catalyst is wetted as soon as it enters the catalyst receiver. These operations are carried out under air.

\subsubsection{Measures to Prevent Explosive Hydrogen/Air Mixtures}

The following measures were taken to avoid explosive hydrogen/air mixtures in the reactor, receivers, catalyst filter and tubes on one hand as well as the plant hall on the other side (Fig. 6): (1) Complete inertization of vessels before loading with hydrogen; (2) gases from inertization (including gas from evacuation) are released only into inertized waste gas collector; (3) double mechanical seals (sealing liquid under pressure, pressure of sealing liquid higher than reaction pressure, in case of sealing liquid pressure below set threshold pressure, then alarm); (4) good ventilation in plant; (5) sensors for combustible gases (combustible gases, non specific) in plant on top of stirred tank reactors; (6) appropriate definition of Ex-zone: EExdeIICT6; (7) to avoid suction of air into reactors, subatmospheric pressure is avoided during process, except for inertization under controlled conditions; (8) in order to enable opening of all system parts without risks, a sufficient number of open/close valves and flush connections are installed. 


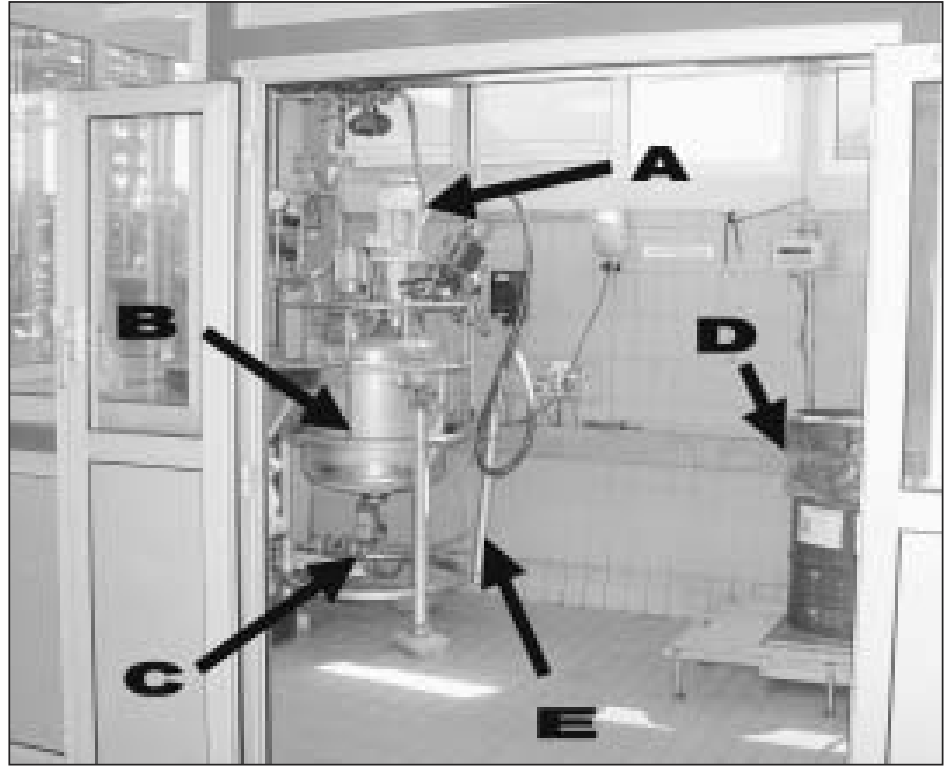

Fig. 5. Separate cabin for preparation of catalyst/diene slurry (can be closed and easily cleaned in case of catalyst spills); $\mathrm{A}=$ suction stirrer (Ystrahl), B = catalyst slurry preparation and feed tank, $C=$ tube for transfer of catalyst slurry to reactor, $\mathrm{D}=$ container with catalyst from supplier, $\mathrm{E}=$ nozzle for suction of catalyst

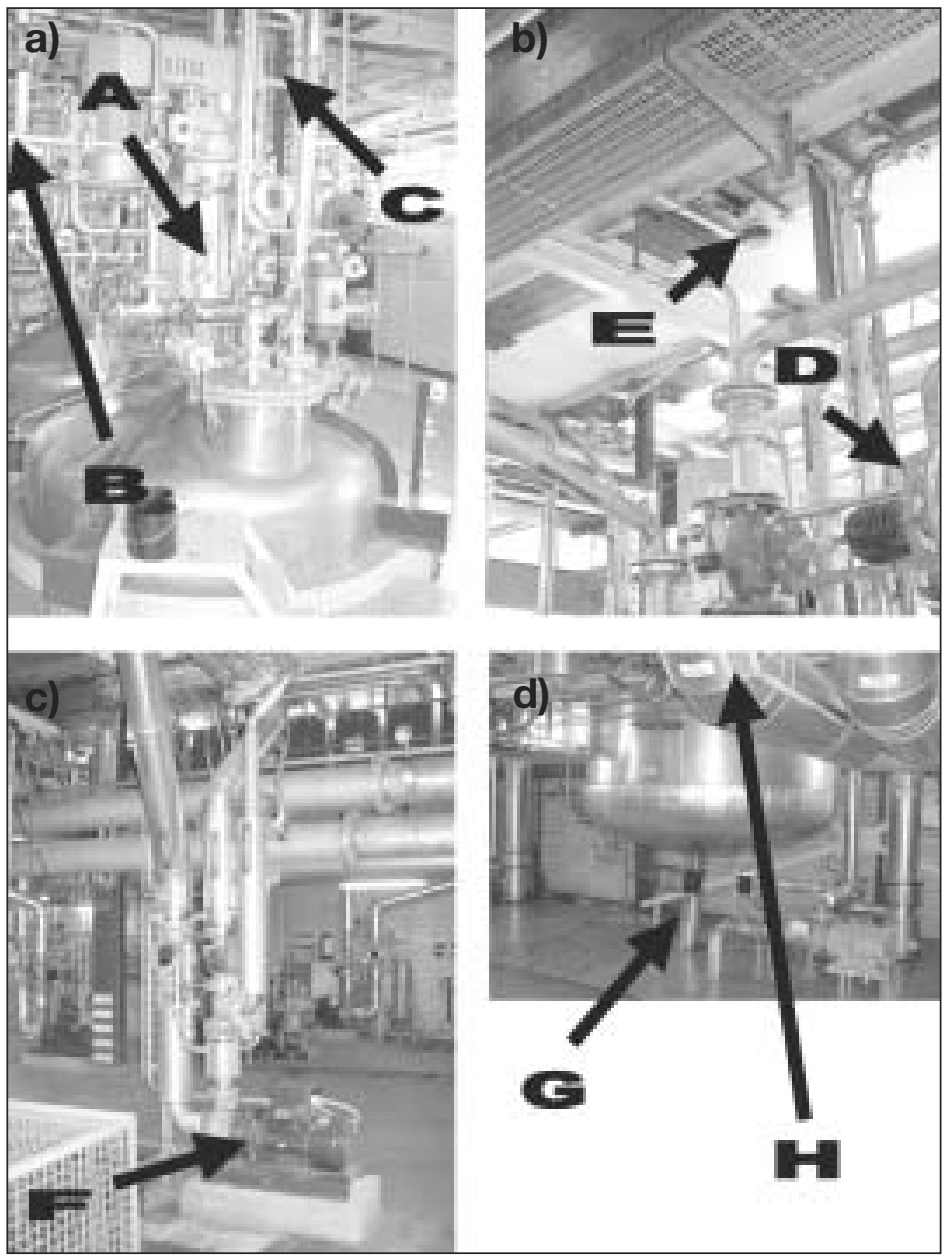

Fig. 6a-d. Safety devices: $A=$ mechanical seal with sealing liquid under pressure (pressure sealing liquid $>$ pressure in reactor), $B=$ flexible tube for hydrogen feed (to avoid rupture by material fatigue), $\mathrm{C}=$ flame barrier for all gases leaving reactor, $\mathrm{D}=$ pressure reduction valve (to adjust pressure in reactor), $E=$ sensor on top of reactor, $F=$ leak proof magnet driven pump for pumping liquid to filter feed tank, $G=$ no bottom sampling, $\mathrm{H}=$ cooling to keep reaction temperature between $80-100{ }^{\circ} \mathrm{C}$

\subsubsection{Measures to Prevent High Reaction Temperatures During} the Process (Control of Reaction Rate)

In order to avoid exceeding the upper temperature limit of the process and runaway situation, the following actions were taken: (1) The reaction is run in a semibatch mode: by this technique, one of the reaction partners (hydrogen) is fed continuously, i.e. its concentration in the reactor can always be kept at a low value, and if desired the hydrogen flow can be turned off to stop heat production by hydrogenation; (2) the reaction is run non-isothermally until the design temperature $\left(80-100{ }^{\circ} \mathrm{C}\right)$ is reached; (3) when the design temperature is reached, the hydrogen pressure is set to a lower value. This results in a lower gas/liquid transport rate (reaction rate is gas/liquid transport limited) which allows to keep the temperature constant by means of the available cooling (Fig. 7); (4) finally when the hydrogenation slows down, the pressure is increased to 1.3 barg.

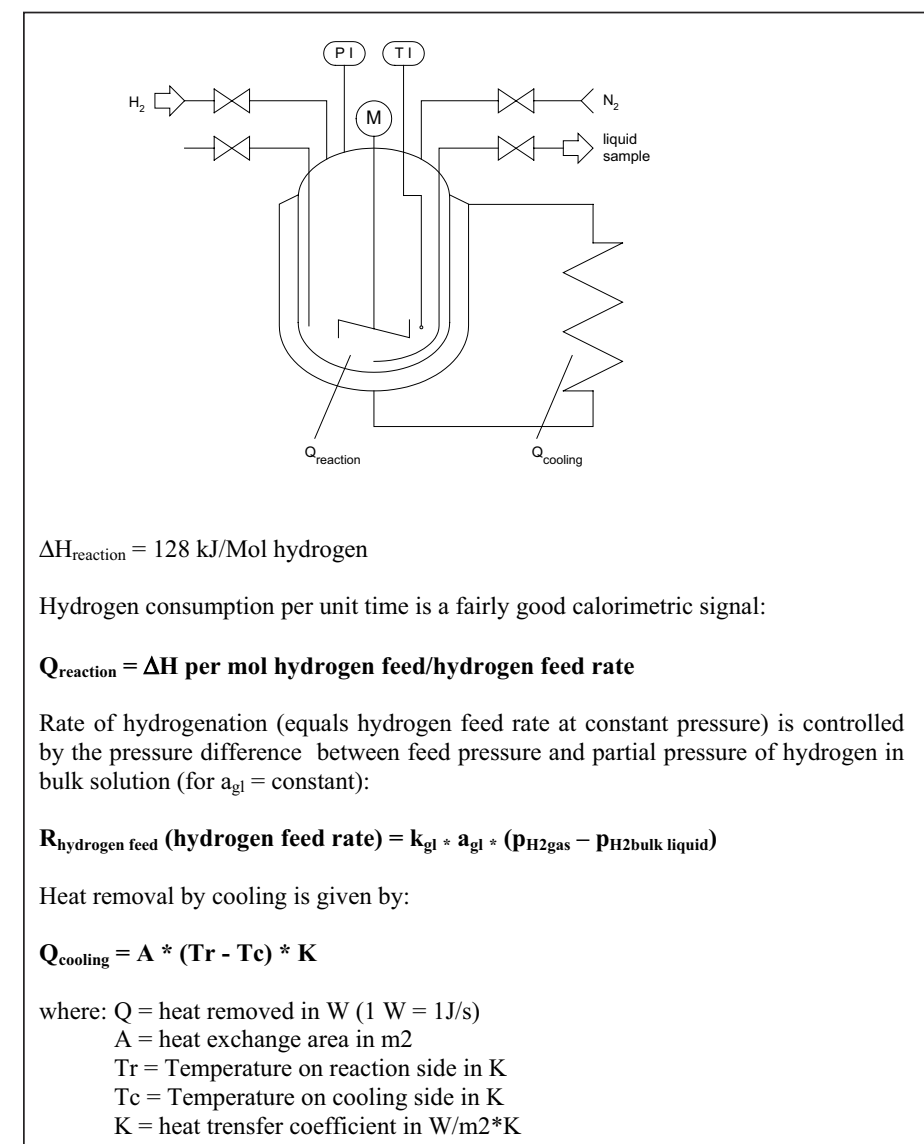

Under equilibrium conditions the heat production by chemical reaction equals heat removal by cooling, i.e

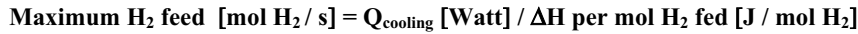

Fig. 7. Semi-batch reaction mode, heat balance and maximum reaction rate 


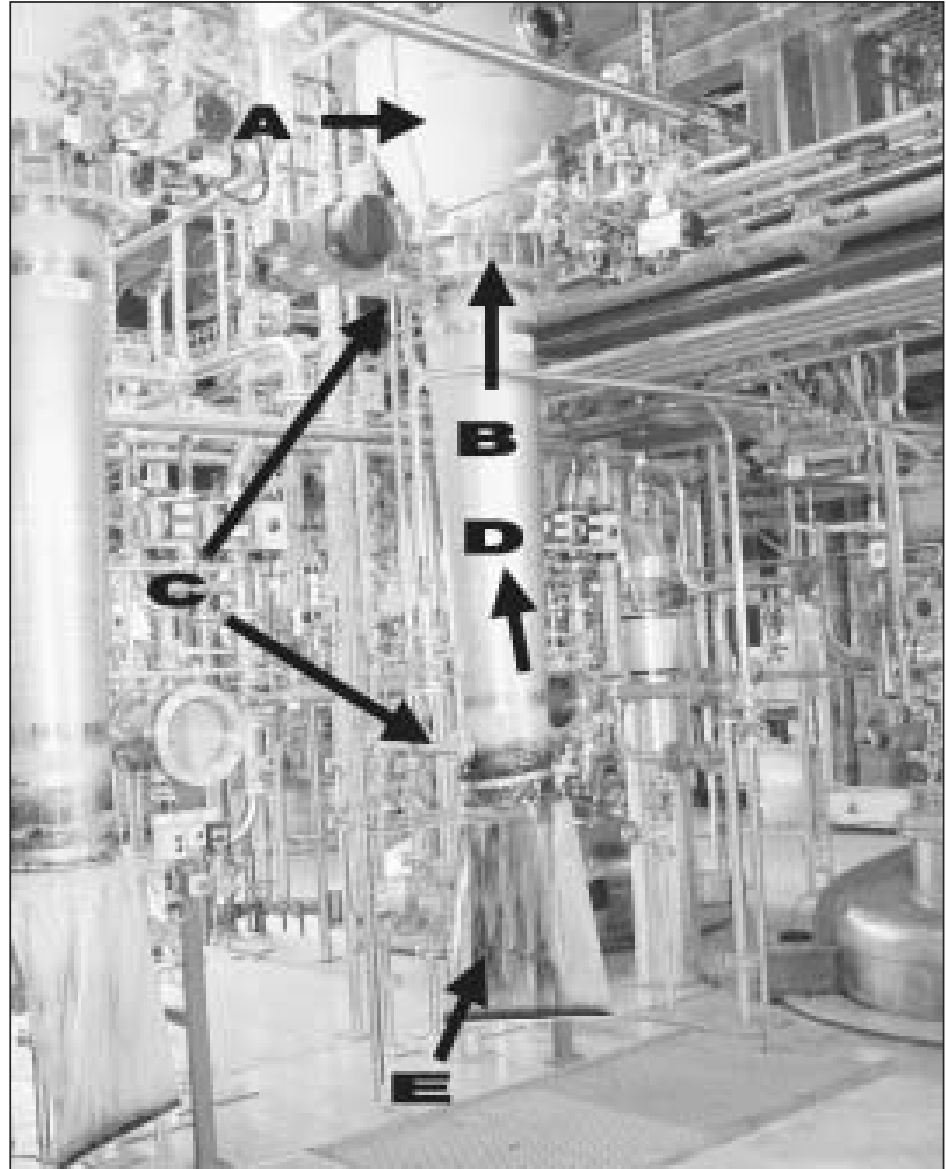

Fig. 8. Unloading spent catalyst; $A=$ backflush filter housing, $B=$ lock, $\mathrm{C}=$ tubes for inertization, $\mathrm{D}=$ permanent inertization, $\mathrm{E}=$ plastic bag with spent catalyst (new version: steel container)

\subsubsection{Prevention of Ignition} of Pyrophoric Catalyst After Filtration

In order to avoid contact of spent catalyst with air, the transfer of spent catalyst is carried out under nitrogen (Fig. 8).

\subsubsection{Ignition Sources}

In order to avoid ignition by catalyst, the following actions were taken: (1) The plant, particularly the zones where the presence of hydrogen is most probable, is kept essentially free of catalyst dust; (2) catalyst addition device is placed in a separate compartment, and even there catalyst spill is avoided by a special device for the transfer of catalyst from the catalyst container to the catalyst/slurry vessel; (3) catalyst filtration units and devices to unload spent catalyst are placed in compartments far away from the hydrogenation reactors and operations are carried out under nitrogen. Special attention is given to keep the catalyst unloading area clean and free of catalyst.

\subsubsection{Prevention of Flame Propagations}

In order to prevent propagation of flames, flame barriers are installed in all gas tube connections with the reactor.

\subsubsection{Prevention of Spills}

In order to avoid spills, the following measures are taken: (1) To avoid leakage by squeezed sealings, tongue and groove type flanges are used; (2) in order to prevent rupture of tubings by vibrations, hydrogen feed to reactor is via flexible tubes; (3) regular control of tightness and stability against pressure (reactor $10 \mathrm{barg}$ ); (4) in case of overpressure in reactor due to overfilling: safety valve and expansion to blow down vessel; (5) in case of overpressure in reactor due to chemistry (explosion of hydrogen/air mixture, decomposition of diene): design pressure of reactor (7 barg) together with safety valve sufficient to survive explosion of hydrogen/air mixture; safety valve with expansion to blow down tank; (6) safe liquid sampling device; (7) hydrogen comes in with a maximum pressure of 2.0 barg (reaction pressure $1.3 \mathrm{barg}$ ); safety valve with 2.0 barg (control by external expert not compulsory); (8) bottom valve is fire proof; (9) provisions to stop liquids entering gas feed tubes in backward direction; (10) use of resistant and compatible materials.

\subsubsection{Emergency Measures}

In case of emergency (spillage, fire etc.) local and sector emergency switch off buttons are installed.

Received: October 3, 2003

[1] W.R. Tong, R L. Seagrave, R. Wiederhorn, Loss Prevention Bulletin 1977, 11, 71-75.

[2] Schriftenreihe der Expertenkommission für Sicherheit in der chemischen Industrie der Schweiz (ESCIS), 1986, Heft 4, 2. Auflage.

[3] 'Handbuch des Explosionsschutzes', Ed. H. Sten, Wiley-VCH-Verlag, Weinheim, 2000 